\title{
Dysferlin-mediated membrane repair protects the heart from stress-induced left ventricular injury
}

\author{
Renzhi Han,1,2,3,4,5 Dimple Bansal,1,2,3,4,5 Katsuya Miyake, 6 Viviane P. Muniz,1,2,3,4,5
}

Robert M. Weiss, ${ }^{2,5}$ Paul L. McNeil, 7 and Kevin P. Campbell1,2,3,4,5

\begin{abstract}
${ }^{1}$ Howard Hughes Medical Institute, ${ }^{2}$ Senator Paul D. Wellstone Muscular Dystrophy Cooperative Research Center, ${ }^{3}$ Department of Molecular Physiology and Biophysics, ${ }^{4}$ Department of Neurology, and ${ }^{5}$ Department of Internal Medicine,

Roy J. and Lucille A. Carver College of Medicine, The University of lowa, lowa City, lowa, USA. ${ }^{6}$ Institute of Molecular Medicine and Genetics and ${ }^{7}$ Department of Cellular Biology and Anatomy, Medical College of Georgia, Augusta, Georgia, USA.
\end{abstract}

\begin{abstract}
Dilated cardiomyopathy is a life-threatening syndrome that can arise from a myriad of causes, but predisposition toward this malady is inherited in many cases. A number of inherited forms of dilated cardiomyopathy arise from mutations in genes that encode proteins involved in linking the cytoskeleton to the extracellular matrix, and disruption of this link renders the cell membrane more susceptible to injury. Membrane repair is an important cellular mechanism that animal cells have developed to survive membrane disruption. We have previously shown that dysferlin deficiency leads to defective membrane resealing in skeletal muscle and muscle necrosis; however, the function of dysferlin in the heart remains to be determined. Here, we demonstrate that dysferlin is also involved in cardiomyocyte membrane repair and that dysferlin deficiency leads to cardiomyopathy. In particular, stress exercise disturbs left ventricular function in dysferlin-null mice and increases Evans blue dye uptake in dysferlin-deficient cardiomyocytes. Furthermore, a combined deficiency of dystrophin and dysferlin leads to early onset cardiomyopathy. Our results suggest that dysferlin-mediated membrane repair is important for maintaining membrane integrity of cardiomyocytes, particularly under conditions of mechanical stress. Thus, our study establishes what we believe is a novel mechanism underlying the cardiomyopathy that results from a defective membrane repair in the absence of dysferlin.
\end{abstract}

\section{Introduction}

Dilated cardiomyopathy is the most common type of cardiomyopathy, a condition that can often progress into heart failure and sudden death. Many cases of dilated cardiomyopathy have a genetic etiology. Indeed, inherited forms of idiopathic dilated cardiomyopathy account for at least $30 \%$ of dilated cardiomyopathy cases. These are a major cause of severe heart failure and necessitate heart transplantation (1). A number of genes encoding sarcomeric and cytoskeletal proteins have been identified as being responsible for dilated cardiomyopathy: cardiac actin, cardiac troponin $\mathrm{T}, \beta$-myosin heavy chain, $\alpha$-tropomyosin, $\alpha$-actinin, titin, metavinculin, and desmin (reviewed in ref. 2). Mutations in genes such as dystrophin $(3,4), \alpha$-sarcogly$\operatorname{can}(5), \beta$-sarcoglycan (6), $\gamma$-sarcoglycan (7), and $\delta$-sarcoglycan $(8,9)$, which encode proteins involved in linking the cytoskeleton, sarcolemma, and extracellular matrix, have also been identified as causes of some familial dilated cardiomyopathy. Such mutations lead to the disruption of the cytoskeleton-sarcolemma-extracellular matrix link and thus render the sarcolemma more susceptible to contraction-induced injury (10-12).

The plasma membrane provides a physical barrier between the extracellular and intracellular environments, and the maintenance of this barrier is crucial for cell survival; however, plasma-membrane disruption occurs physiologically in certain types of cells,

Nonstandard abbreviations used: DGC, dystrophin-glycoprotein complex; DKO, dysferlin/dystrophin double-mutant (mice); EBD, Evans blue dye; LGMD2B, limb-girdle muscular dystrophy type $2 \mathrm{~B}$.

Conflict of interest: The authors have declared that no conflict of interest exists. Citation for this article: J. Clin. Invest. 117:1805-1813 (2007). doi:10.1172/JCI30848. such as skeletal (13) and cardiac muscle (14), due to their large size and the mechanical stress of contraction and relaxation. The frequency of membrane disruption in skeletal and cardiac muscle cells is directly dependent on the level of physical activity $(13,14)$. In skeletal muscle, membrane disruption is known to initiate a rapid $\mathrm{Ca}^{2+}$-dependent membrane-repair process (15) that allows the damaged cells to reseal their membranes, which is essential for their survival. An active membrane repair is therefore required to eliminate the cellular cost of replacing large and/or frequently injured skeletal muscle cells. Dysferlin has been shown to play a pivotal role in the membrane-repair pathway of skeletal muscle, and dysferlin deficiency leads to defective membrane resealing in skeletal muscle $(15,16)$. The failure to reseal membrane disruptions and the consequent $\mathrm{Ca}^{2+}$ entry through the disruption sites leads to activation of $\mathrm{Ca}^{2+}$-triggered proteases and rapid cell death cascade (which can occur within seconds). In humans, dysferlin deficiency leads to 3 clinically distinct forms of muscular dystrophy: limb-girdle muscular dystrophy type 2B (LGMD2B) (17), Miyoshi myopathy (18), and a distal myopathy with anterior tibial onset (19). Similarly, dysferlin-deficient mice develop a pronounced limb-girdle muscular dystrophy $(15,20,21)$. Therefore, the rapid resealing of membrane disruptions in skeletal muscle is required to maintain the plasma membrane integrity of the cells, which is in turn essential for the normal structure and function of skeletal muscle.

Notably, a 57-year-old Japanese woman with a $3370 \mathrm{G} \rightarrow \mathrm{T}$ missense mutation in dysferlin was recently reported to manifest ventricular enlargement and diffuse hypokinesia (22). This finding suggests that dysferlin deficiency may induce cardiomyopathy as well as muscular dystrophy. However, as this remains the only 

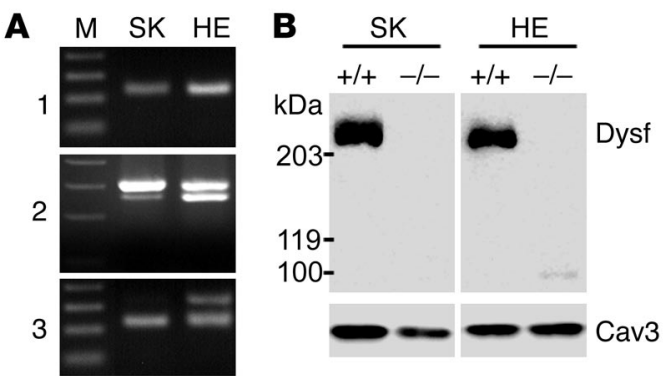

C

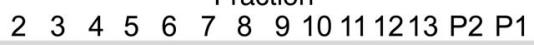

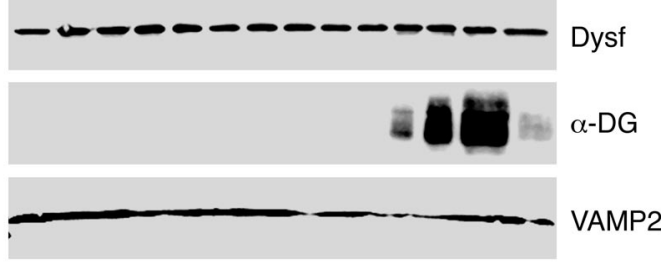

report of cardiac involvement in a dysferlin-deficient patient, it is not clear whether the dysferlin deficiency is the primary cause of the cardiomyopathy in this case. With respect to this question, however, a recent meeting abstract reporting elevated tropin levels in 9 of 11 (81\%) European dysferlin patients ranging in age from 19 to $48(23)$ is of interest. Although none of these patients had developed overt cardiomyopathy at the time of reporting, following them for the development of this condition over time as part of a systematic investigation involving an extended group of patients of matching age may clarify whether the dysferlin deficiency can ultimately lead to cardiac abnormality.

It is reasonable to conjecture that dysferlin may play an important role in the heart. Dysferlin has been shown to be highly expressed in the rat heart (24), and because cardiac muscle undergoes intensive mechanical activity similar to that experienced by skeletal muscle, it may also require a robust membrane resealing mechanism. We thus hypothesized that dysferlin deficiency leads to defective repair of cardiomyocytes following membrane disruption and thus to cardiomyopathy. To test these hypotheses, we studied cardiac function and myocyte membrane-repair capacity in the hearts of dysferlin-null mice. Our data show that dysferlin is an important component of the $\mathrm{Ca}^{2+}$-dependent membrane-repair mechanism in cardiomyocytes, that dysferlin deficiency leads to cardiomyopathy, and that this condition can be worsened by either stress exercise or the loss of dystrophin.

\section{Results}

Dysferlin is expressed in cardiac muscle. We first examined dysferlin expression in the hearts of WT mice by RT-PCR and immunoblotting. The dysferlin transcript can be amplified from both the skeletal muscle and heart using a pair of primers designed to complement the 5 ' region of the gene (Figure 1A). An alternatively spliced variant lacking a 42-bp exon (exon 17) had previously been reported in human muscle cells (25). We found that the isoform with the 42-bp exon is the predominant one in mouse skeletal muscle whereas cardiac muscle expresses similar levels of both isoforms (Figure 1A). We detected another isoform of dysferlin, which we believe to be novel, that shows an alternatively spliced, in-frame, 93-bp exon (Figure 1A) immediately after exon 5. The presence

\section{Figure 1}

Expression and subcellular localization of dysferlin in cardiac muscle. (A) Dysferlin transcripts were amplified by different primer sets (nos. 1-3) from the total RNA extracted from the WT mouse skeletal muscle (SK) and heart (HE). (B) Dysferlin (Dysf) proteins were detected among the SDS-extracted proteins of WT skeletal muscle and heart but not among those extracted from dysferlin-null skeletal muscle and heart. Caveolin-3 (Cav3) was detected and served as the loading control. (C) Subcellular membrane fractionation of heart homogenates from WT mice (see Methods for details) showed that dysferlin is localized in the plasma membrane (fractions 12 and 13; pellet 2) and in the intracellular vesicle fractions (fractions $2-11$ ). $\alpha-D G$, anti- $\alpha$-dystroglycan; $\mathrm{M}$, molecular weight marker.

of this isoform is very low in adult skeletal muscle but high in the heart. Immunoblotting of WT heart SDS-extracted proteins with the dysferlin antibody Hamlet, which was raised against the dysferlin $\mathrm{C}$ terminal region, detected a band of approximately $230 \mathrm{kDa}$, and hearts from the dysferlin-null mice were completely devoid of dysferlin protein (Figure 1B). Anti-caveolin-3 antibody was used as a loading control.

To determine the subcellular distribution of dysferlin in normal cardiomyocytes, sucrose gradient membrane fractionation was performed after homogenizing WT hearts. Dysferlin was detected in both the fractions that were enriched for plasma membrane and those that were enriched with intracellular vesicle markers such as VAMP2 (Figure 1C) and the transferrin receptor (data not shown).

Dysferlin is required for the membrane repair of cardiac muscle. Our data showing that dysferlin is highly expressed in cardiac muscle and that it is present in vesicles as well as in the plasma membrane lent support to our hypothesis that this protein may be involved in the repair of cardiac muscle membranes. However, it was not known whether normal cardiomyocytes possess a $\mathrm{Ca}^{2+}$-dependent membrane-repair capacity similar to that of skeletal muscle. To directly address this issue, we developed an in situ membranerepair assay with which to test the cardiomyocytes of the WT mice. First, the membranes of cardiomyocytes were wounded by full-power irradiation with a mode-locked infrared laser in the presence of the membrane-impermeable dye FM 1-43, a watersoluble molecule that becomes fluorescent when it partitions into a membrane and does not cross it (the assay was conducted on surface cardiomyocytes of heart slices to assure easy dye accessibility). Upon laser-induced membrane wounding (Figure 2A), the plasma membranes of WT cardiomyocytes were efficiently resealed in the presence of $\mathrm{Ca}^{2+}$. This was indicated by the observation that in the presence of $\mathrm{Ca}^{2+}$, the FM 1-43 fluorescence intensity initially increased but halted within 1-2 minutes whereas the FM 1-43 fluorescence intensity continuously increased in the absence of $\mathrm{Ca}^{2+}$ (Figure 2, A and B). Thus, like skeletal muscle, cardiac muscle appears to possess an active and efficient, $\mathrm{Ca}^{2+}$-dependent membrane-repair mechanism. Testing the membrane-repair efficiency of the cardiomyocytes from the dysferlin-null mice, we found that even in the presence of $\mathrm{Ca}^{2+}$, the cardiomyocytes from the dysferlinnull heart slices could not effectively reseal the wounded plasma membranes (Figure 2, A and B). This result clearly suggests that dysferlin is an important component of the membrane-repair machinery in the cardiac muscle.

Dysferlin-null mice develop mild cardiomyopathy. To determine whether the defective membrane repair in cardiac muscle due to dysferlin deficiency leads to any cardiac abnormality, we conduct- 


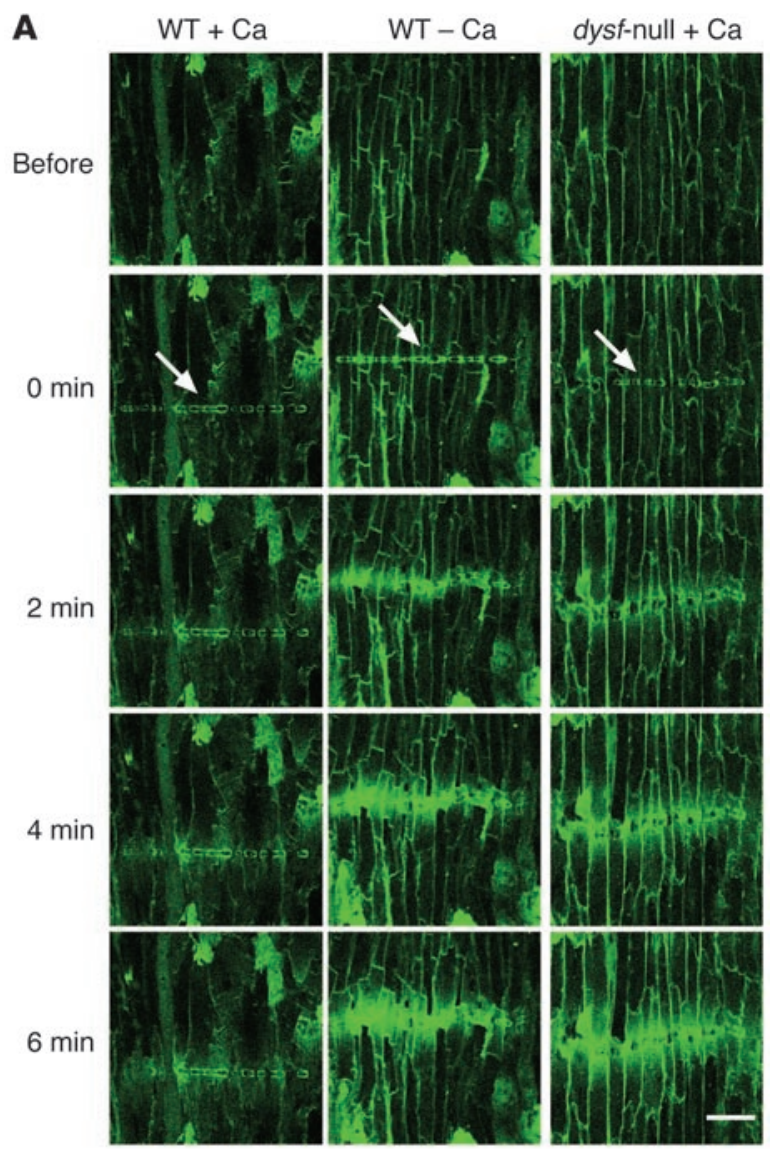

B

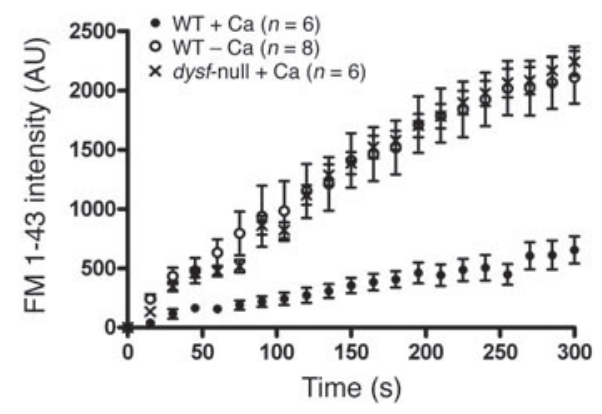

ed a histological analysis of heart sections from dysferlin-null mice and age-matched controls and also measured the serum levels of cardiac troponin $\mathrm{T}$ in these animals.

H\&E examination of the heart sections from the dysferlin-null mice that were less than 32 weeks old did not reveal a remarkable pathological change (data not shown). However, heart sections of the dysferlin-null mice that were 56 weeks old showed sporadic necrotic fibers (Figure 3, D and G), and these necrotic fibers were observed more frequently in 80-week-old dysferlin-null mice (Figure 3, E and $\mathrm{H}$ ). Only rarely were necrotic fibers observed in the hearts of the age-matched controls (Figure 3, A and B). As revealed by Sirius red staining, cardiac fibrosis was present in aged dysferlinnull mice (Figure 3, F and I) but not in aged WT controls (Figure 3C). Total collagen deposits in aged dysferlin-null mice were significantly higher ( $\sim$-fold) than in WT controls (Figure 3J).

Troponin $\mathrm{T}$ is a cardiac muscle-specific structural protein that is impermeable to the plasma membrane, and it is undetectable in the

\section{Figure 2}

Membrane damage-repair assay in cardiomyocytes in left ventricle slices from normal and dysferlin-null mice. (A) Left panel: WT cardiomyocytes in the presence of physiological $\mathrm{Ca}^{2+}(\mathrm{WT}+\mathrm{Ca})$; middle panel: WT cardiomyocytes in the absence of physiological $\mathrm{Ca}^{2+}$ (WT - Ca); right panel: dysferlin-null cardiomyocytes in the presence of physiological $\mathrm{Ca}^{2+}(d y s f-n u l l+\mathrm{Ca})$. Arrows indicate sites of laser damage. Scale bar: $50 \mu \mathrm{m}$. (B) Quantitative analysis of the membranerepair assay of normal and dysferlin-null cardiomyocytes.

serum under normal physiological conditions. However, in the case of several abnormal cardiac conditions in which cardiac muscle undergoes active necrosis (including cardiomyopathy), troponin $\mathrm{T}$ is released into the bloodstream and can be detected at high levels in the serum (26). We measured the resting serum troponin T levels in the dysferlin-null mice of 2 age groups (30 and 70 to 90 weeks old) (Figure 3K). Of the 8 dysferlin-null mice ( 30 weeks old), 5 had mildly elevated $(\sim 7$-fold increase) serum troponin T levels $(0.074 \pm 0.015 \mathrm{ng} / \mathrm{ml}$, $n=5)$ whereas none of the age-matched controls $\mathrm{did}(<0.010 \mathrm{ng} / \mathrm{ml}$, $n=10)$. In the 70 - to 90 -week-old group, 17 of the 26 dysferlin-null mice had increased serum troponin T levels $(0.092 \pm 0.013 \mathrm{ng} / \mathrm{ml}$, $n=17)$ whereas the serum troponin T levels in all of the age-matched controls was under the level of detection $(<0.010 \mathrm{ng} / \mathrm{ml}, n=15)$.

Stress exercise exacerbates the cardiomyopathy in dysferlin-null mice. To determine whether the dysferlin-null mice are likely to develop a more pronounced cardiac abnormality when their hearts are subjected to mechanical stress, we first recorded echocardiography to compare the cardiac function of the dysferlin-null mice before and after stress exercise. When the mice were 54 weeks of age, stress exercise significantly reduced the heart rate of the dysferlin-null mice (668 $\pm 15 \mathrm{~min}^{-1}$ before and $615 \pm 12 \mathrm{~min}^{-1}$ after exercise, $n=9$; $P<0.01)$ but did not affect that of the control mice $(n=6 ; P=0.33)$ (Figure 4A). After stress exercise, the dysferlin-null mice had a significantly increased left ventricular end-systolic volume $(9.9 \pm 1.1 \mu \mathrm{l}$ before and $19.0 \pm 2.2 \mu \mathrm{l}$ after exercise; $P<0.01$ ), which was not affected by the stress exercise in the control mice $(8.3 \pm 2.3 \mu \mathrm{l}$ before and $8.8 \pm 2.2 \mu \mathrm{l}$ after; $P=0.85$ ) (Figure $4 \mathrm{~B}$ ). Stress exercise also tended to increase the left ventricular end-diastolic volume of the dysferlin-null mice ( $49.1 \pm 3.6 \mu \mathrm{l}$ before and $60.9 \pm 2.5 \mu \mathrm{l}$ after) although the difference between exercised and nonexercised animals was not statistically significant $(P=0.06)$. However, relative to the left ventricular end-diastolic volume of the exercised control mice, that in the exercised dysferlin-null mice was considered to be significantly different $(P=0.003)$ (Figure 4C). Finally, the left ventricular ejection fraction of the dysferlin-null mice but not of the controls was significantly decreased by the stress exercise $(P=0.02)$ (Figure 4D). These results suggest that the dysferlin-null mice develop exerciseinduced systolic dysfunction and pathological chamber dilation.

The Evans blue dye (EBD) uptake analysis of the heart before and after the stress exercise was also performed in order to determine whether subtle damage to myocytes occurs at early stages and in response to exercise. In 24-week-old dysferlin-null mice, which usually do not show any pronounced abnormalities in heart sections, sporadic EBD-positive myocytes were observed (Figure 4E) after stress exercise. This was not the case in hearts from either the nonstressed dysferlin-null mice or the stressed WT mice (data not shown). H\&E staining of the matched sections showed fiber necrosis in dysferlinnull mice after stress exercise (Figure 4E). Collectively, these results suggest that the stress exercise initiates the left ventricular dysfunction at both the cellular and tissue levels in dysferlin-null mice. 


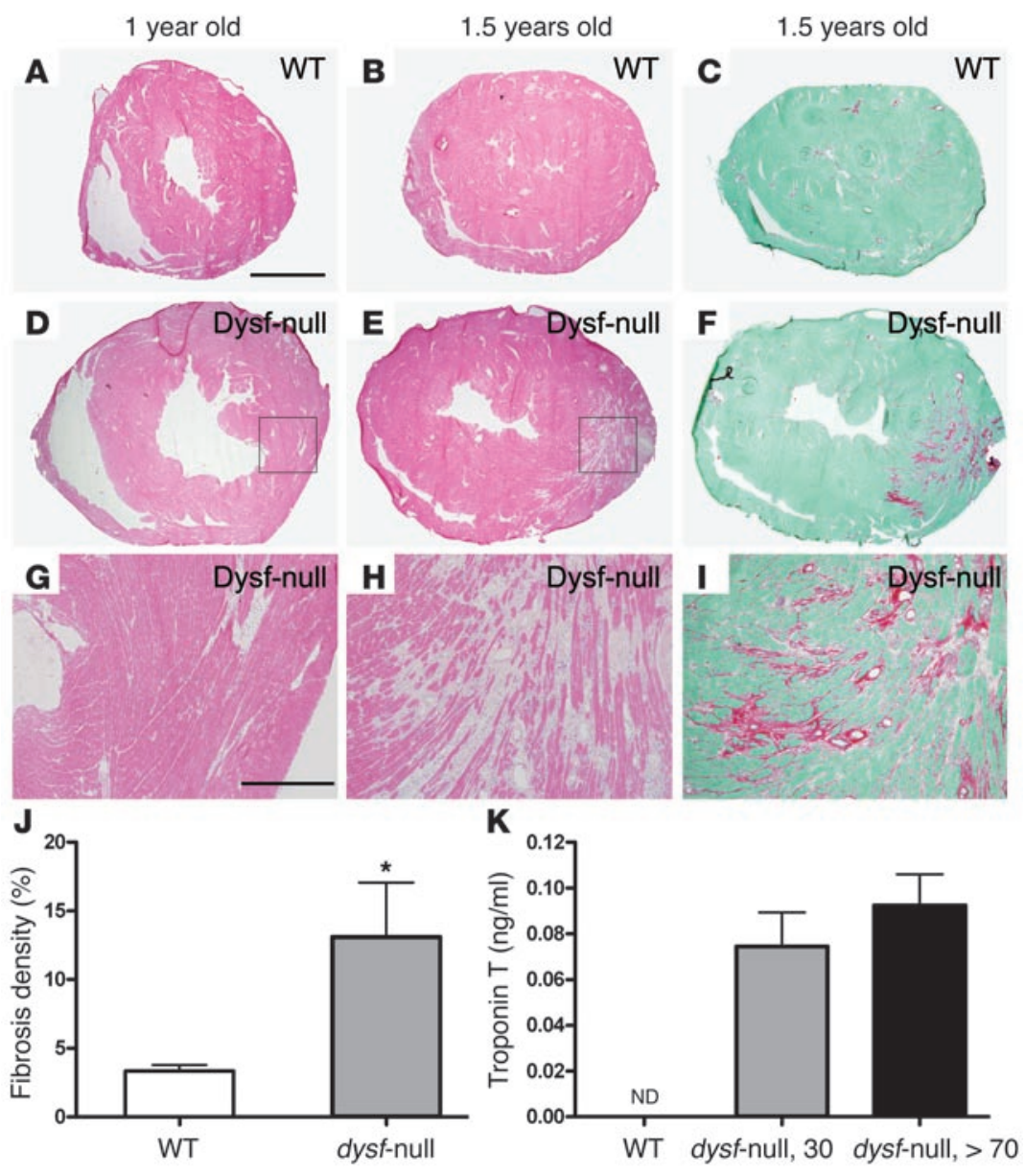

Figure 3

Mild cardiomyopathy in senescent dysferlin-null mice. H\&E staining of heart sections revealed necrosis and fibrosis in cardiac muscle of dysferlin-null mice (D, E, G, H) but not in WT mice (A and $\mathbf{B})$. Sirius red staining $(\mathbf{C}, \mathbf{F}, \mathbf{I})$ showed increased collagen deposits in aged dysferlin-null mice. Scale bars: $2 \mathrm{~mm}(\mathbf{A}-\mathbf{F}) ; 500 \mu \mathrm{m}(\mathbf{G}-\mathbf{I})$. H\&E and Sirius red staining images were representatives of at least 4 mice in each group. (J) Quantitative analysis of total cardiac collagen deposits revealed about a 3-fold increase in aged dysferlin-null mice ( $n=6$ for each group; ${ }^{*} P=0.03$, unpaired Student's $t$ test). (K) Serum troponin T was mildly elevated in the dysferlin-null mice at $30(n=5)$ and 70-90 weeks of age $(n=17)$ but not detected (ND) in age-matched WT mice ( $n=10$ for each age group).

Dysferlin-mediated membrane repair minimizes the pathological changes in cardiac muscle. In contrast to dysferlin, dystrophin is an integral component of the dystrophin-glycoprotein complex (DGC), which is present on the plasma membrane and connects the extracellular matrix to the intracellular cytoskeleton (10). Mutations in any of the DGC components disrupt the stability of the DGC within the plasma membrane $(27,28)$, which in turn breaks the transmembrane link between the extracellular matrix and the intracellular cytoskeleton. Loss of this link renders the muscle membrane susceptible to contraction-induced injuries $(10-12,29,30)$. This suggests that a robust membrane-repair capacity may be extremely important for minimizing the muscle cell loss in the DGC-linked muscular dystrophies. We therefore hypothesized that the dysferlin/ dystrophin double-mutant (DKO) mice would develop more severe cardiac muscle pathology than mice mutant for either gene alone, owing to an increased susceptibility to muscle membrane injuries due to dystrophin loss and to defective membrane repair due to dysferlin loss. To test this possibility, we generated a DKO mouse model by crossing dysferlin-null mice with $m d x$ mice, a mouse model of Duchenne muscular dystrophy lacking dystrophin (31-33). The latter model is widely used to study Duchenne muscular dystrophy and carries a mutation that eliminates expression of the $427-\mathrm{kDa}$ muscle and brain isoforms of dystrophin.

The loss of dystrophin and dysferlin in the skeletal muscles of DKO mice was confirmed by immunoblotting and immunofluorescence analysis (Supplemental Figure 1; supplemental material available online with this article; doi:10.1172/ JCI30848DS1). This entailed a comparative histological analysis of the cardiac muscles, with heart sections taken every $200 \mu \mathrm{m}$ from the apex to the base so that even highly regionalized histopathological changes to the heart would be detected. Acute cardiac muscle necrosis and fibrosis were observed in DKO mice as young as 11 weeks of age (Figure 5, D-I). In contrast, no apparent necrosis/fibrosis could be detected in littermate $m d x$ (Figure 5, A-C) or dysferlin-null mice (not shown) at even 16 weeks of age. Although small regions of fibrosis could be seen in older $m d x$ and dysferlin-null mice, those about 1 year old (see Figure 3, D-I), the pathology was never as severe as that observed in DKO mice. The serum troponin T levels measured in 10- and 18-week-old DKO mice were nearly 20 -fold and over 38-fold higher (Figure 5K), respectively, suggesting that necrosis was actively occurring in cardiac muscle. At 18 weeks old, both dysferlin-null and $m d x$ mice showed the same basal levels of serum troponin T levels as WT animals.

The mice were also exposed to stress exercise, and this was found to induce large areas of acute necrosis in 9-week-old DKO mice (Figure 6, A-D) but little to no acute necrosis in $m d x$ or dysferlinnull mice of the same age (data not shown). The postexercise EBD uptake analysis revealed very large areas of EBD uptake in the cardiac muscles of DKO mice (Figure 6G). We again analyzed sections taken at $200-\mu \mathrm{m}$ intervals throughout the heart and detected EBD-positive tissue in all sections whereas EBD-positive tissue was limited to small localized areas in $m d x$ (Figure 6F) and dysferlin-null mice (Figure 6E). No EBD-positive tissue was seen in WT mice.

Dysferlin does not protect ischemic cardiomyopathy. Despite significant advances in our understanding of coronary disease over the past 2 decades, coronary ischemic artery disease remains the predominant cause of premature death (34). To investigate whether dysferlin-mediated membrane repair plays a role in myocardial ischemia, we performed a coronary artery ligation experiment in WT and dysferlin-null mice. WT $(n=17)$ and dysferlin-null $(n=24)$ mice were subjected to myocardial infarction by permanent ligation of the proximal left coronary artery. We did not observe any statistically significant differences between genotypes with respect to mortality or echocardiographically determined initial infarct size, ejection fraction, or the extent of left ventricular remodeling 2 weeks after infarct (Supplemental Figure 2). 

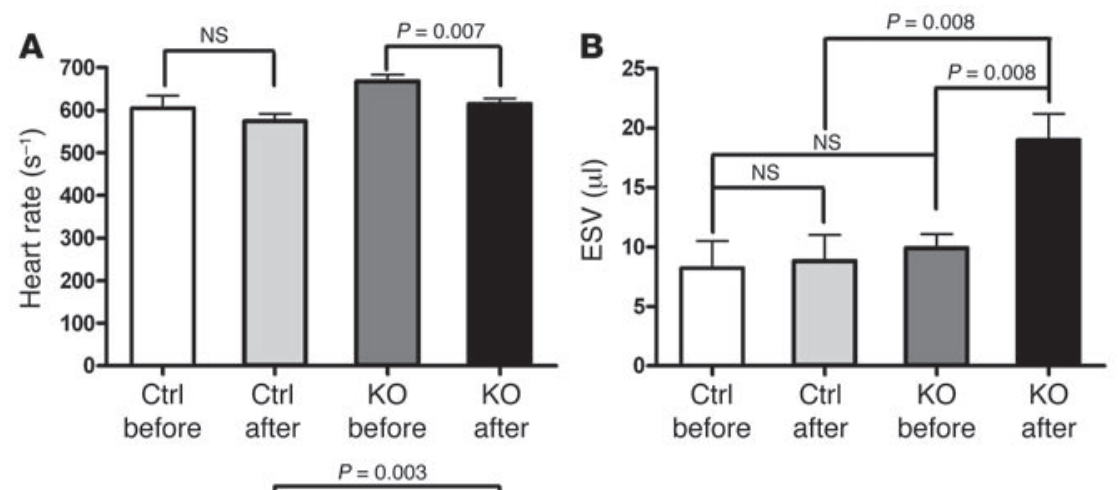

cardiomyopathy. The observation that stress exercise and loss of dystrophin greatly exacerbate the cardiac manifestations of disease in the dysferlin-null mice suggests that the dysferlin-mediated membrane repair is indispensable for maintaining the sarcolemma integrity of cardiomyocytes.

Dysferlin expression in the mouse heart was confirmed by RT-PCR and immunoblotting in the present study. The fact that we have identified several splice variants of dysferlin in the heart muscle implies that dysferlin regulation is more complex in the heart than in skeletal muscle and that this protein may have greater functional diversity than previously appreciated. Furthermore, subcellular membrane fractionation of the heart muscle suggests that dysferlin is localized to both the sarcolemma and some unidentified type of vesicles, which is consistent with a role in the membrane-repair process. However, the nature of the dysferlin vesicles and the exact mechanism underlying the dysferlin-mediated membrane repair remain to be determined.

Dysferlin is predicted to have 7 C2 domains, which in other proteins are known to mediate $\mathrm{Ca}^{2+}$ and phospholipid binding as well as protein-protein interaction. The first $\mathrm{C} 2$ domain of dysferlin has been shown to bind phospholipid in a $\mathrm{Ca}^{2+}$-dependent manner (35). Dysferlin has also been shown to bind annexins $\mathrm{A} 1$ and $\mathrm{A} 2$ following membrane injury in a $\mathrm{Ca}^{2+}$-dependent manner, and the distribution of these annexins after injury is significantly altered in dysferlin-deficient skeletal muscle (16), suggesting their involvement in the dysferlin-mediated membrane-repair mechanism. The involvement of annexin A1 in membrane repair is further supported by a recent report showing that inhibiting its function - using an annexin A1 function-blocking antibody, a small peptide competitor of annexin A1, or a dominant-negative annexin A1 mutant protein incapable of $\mathrm{Ca}^{2+}$ binding - prevents membrane resealing (36). Synaptotagmin VII-mediated lysosomal exocytosis has also Figure 4

Effect of stress exercise on echocardiography and cardiac uptake of EBD in dysferlin-null mice. Stress exercise significantly decreased heart rate $(\mathbf{A})$ and increased end-systolic volume (ESV) (B) in dysferlin-null mice. End-diastolic volume (EDV) (C) also tended to increase in response to stress exercise in dysferlin-null mice while ejection fraction (EF) (D) decreased in these animals. $n=6$ for control and $n=9$ for dysferlin-null mice. (E) H\&E (bottom panel) and EBD uptake analysis (top panel) showed individual cardiac muscle fiber necrosis and EBD uptake (marked by asterisks) in heart sections of 24-week-old dysferlinnull mice following stress exercise. Scale bar: $100 \mu \mathrm{m}$.

\section{Discussion}

In 1998, mutations in dysferlin were reported as the cause of LGMD2B (17) and Miyoshi myopathy (18), and later they were identified in a distal myopathy with anterior tibial onset (19). Although dysferlin was shown to be widely expressed (with the highest levels in skeletal muscle and heart) (24), the involvement of nonskeletal muscle tissues, especially the heart, in dysferlinopathy patients, has not been systematically investigated. In the present study, we provide what we believe is the first evidence in support of the existence of a $\mathrm{Ca}^{2+}$-dependent mechanism to repair the membrane wounds in cardiomyocytes. In addition, we have shown that dysferlin, which was previously shown to play an important role in the membrane repair of skeletal muscle $(15,16)$, is also involved in the repair of cardiomyocyte membranes and that dysferlin deficiency leads to been implicated in the plasma membrane repair of skeletal muscle, since synaptotagmin VII-deficient mice developed inflammatory myopathy with extensive fibrosis, high serum levels of creatine kinase, and progressive muscle weakness (37). However, it remains to be clarified whether synaptotagmin VII and dysferlin play similar roles in 2 separate membrane-repair mechanisms or different roles in the same membrane-repair pathway.

Our studies in dysferlin-null mice suggest that dysferlinopathy patients may be predisposed to cardiac disease. In support of this, the 57-year-old Japanese woman with a $3370 \mathrm{G} \rightarrow$ T missense mutation in dysferlin (resulting in an amino acid change at position 999 from Trp to Cys) manifested cardiomyopathy after more than 20 years of progressive muscle wasting and weakness (22). Interestingly, a 53-year-old Japanese man with the same $3370 \mathrm{G} \rightarrow \mathrm{T}$ 

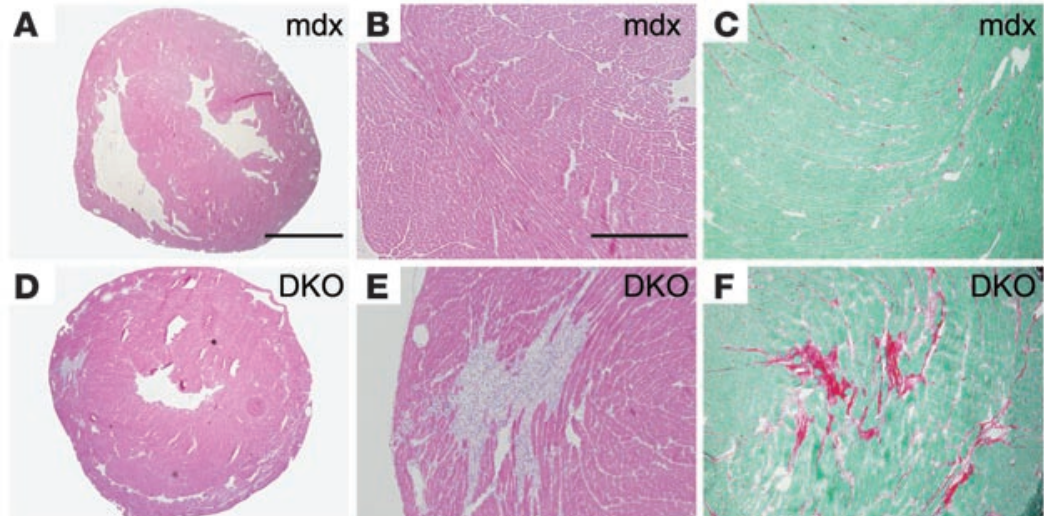
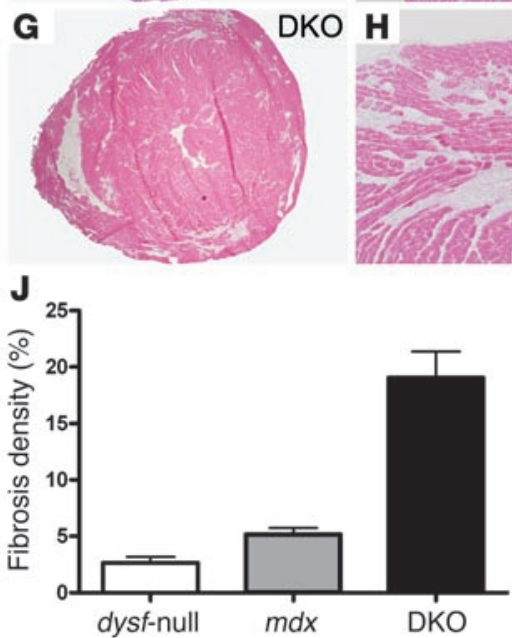
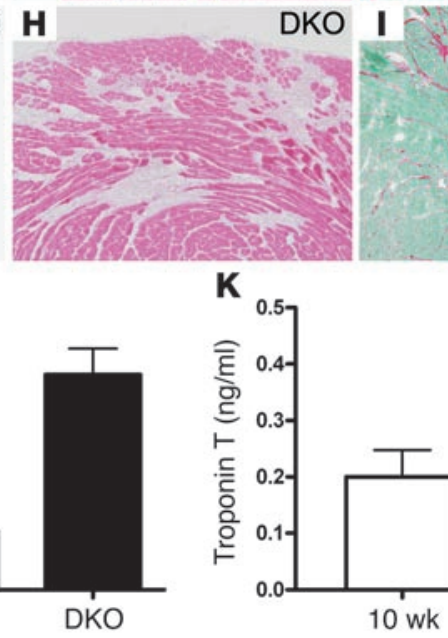



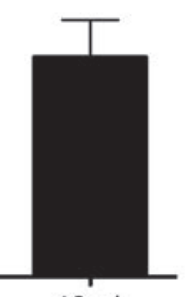

$18 w k$
Figure 5

Severe early-onset cardiomyopathy in DKO mice. Histological examination revealed that the DKO mice presented large areas of necrosis and fibrosis at $11(\mathbf{D}-\mathbf{F})$ and $16(\mathbf{G}-\mathbf{I})$ weeks of age whereas $m d x$ mice $(\mathbf{A}-\mathbf{C})$ did not present any apparent fiber necrosis or fibrosis even by 16 weeks of age. Scale bars: $2 \mathrm{~mm}(\mathbf{A}, \mathbf{D}$, and G); $500 \mu \mathrm{m}$ (B, C, E, F, $\mathbf{H}$, and I). (J) Quantitative analysis of total cardiac collagen deposits in dysferlin-null, $m d x$, and DKO mice at 16 weeks of age $(n=5$ for each group; $P<0.01$ for DKO versus either dysferlin-null or $m d x$ mice). (K) The serum troponin $T$ was dramatically elevated in the 10- $(n=5)$ and 18-week-old DKO mice $(n=5)$.

mutation presented progressive muscle weakness and atrophy as well as progressive choreic movements with no evidence of other causes of chorea (38). Very recently, an immunofluorescence study detected dysferlin expression in neurons of different cortical layers of normal brain and dysferlin accumulation in the neurites throughout the Alzheimer brain and colocalization with amyloid $\beta$ neuritic plaques (39). These studies suggest that, in addition to playing a role in the membrane repair of skeletal and cardiac muscle, dysferlin is important for maintaining normal brain function. Expanding the possible roles for this protein even further, a French group has found that a patient with a $3370 \mathrm{G} \rightarrow \mathrm{T}$ mutation developed glomerular proteinuria (40). Although these reports represent individual clinical cases and their significance is therefore difficult to ascertain, they do point to the possibility that dysferlinopathy may be complicated by manifestations of the disease in a variety of tissues. It is noteworthy that of the 3 cases linked to dysferlin, all share the $3370 \mathrm{G} \rightarrow \mathrm{T}$ mutation. However, it remains unclear whether only this specific mutation can lead to diseases in tissues other than skeletal muscle or other dysferlin mutations are capable of similar effects. Nevertheless, these clinical reports, together with our present study, suggest that dysferlin deficiency may potentially cause abnormalities in a variety of tissues. In addition, our study shows that dysferlin plays an important role in the membrane-repair pathway in both skeletal and cardiac muscle cells, suggesting that defective membrane repair may be a common mechanism that accounts for the disease manifestations in different tissue types in dysferlinopathy patients.

In spite of a lack of systematic investigation regarding cardiac involvement in dysferlin-deficient patients, our study clearly shows that dysferlin-deficient cardiomyocytes are defective in membrane repair and that senescent dysferlin-null mice indeed develop cardiomyopathy. Although we cannot currently rule out the possibility of compensation by other ferlin family proteins (e.g., myoferlin; ref. 41) in cardiac muscle, the most likely reason for the mildness of the cardiomyopathy phenotype in dysferlin-deficient mice is that the heart does not experience excessive mechanical stress under normal laboratory conditions. In support of this notion, we observed that stress exercise exacerbated the cardiac manifestations in dysferlin-null mice and that loss of dysferlin greatly accelerated the progression of cardiomyopathy in $m d x$ mice. These findings suggest that dysferlinopathy-derived overt cardiomyopathy may require a second process (e.g., physical stress) or a second cardiomyopathy-linked gene mutation. However, the fact that our results do not support a protective role of dysferlin in ischemic cardiomyopathy indicates that a functional membrane-repair system is not sufficient for preventing myocardial infarction or helping in recovery. In humans, dysferlinopathy could be expected to exacerbate coexisting conditions such as hypertension or valvular volume overload states, each of which imposes hemodynamic stress upon surviving cardiomyocytes. The contribution of dysferlin deficiency to those processes might not have been accounted for in previous sporadic assessments of cardiac status in patients with coexisting cardiac disease states.

Taken together, our results suggest that the dysferlin-mediated membrane-repair mechanism in the heart becomes very important when coexisting factors lead to more extensive membrane damage (e.g., physical exercise) or compromised membrane integrity (e.g., dystrophin deficiency). Therefore, dysferlin-deficient patients may have to avoid excessive physical stress, which could severely accelerate the manifestation of cardiac disease.

\section{Methods}

Antibodies. The mouse monoclonal antibody Hamlet (Novocastra Laboratories Ltd.), which was raised against dysferlin, was used for Western blotting and immunofluorescence analysis. Monoclonal antibody IIH6 against $\alpha$-dystroglycan, rabbit polyclonal antibody against $\beta$-dystroglycan, and monoclonal antibody against caveolin-3 (BD Biosciences) were used for immunofluorescence and Western blot analysis. The anti-lam- 
A
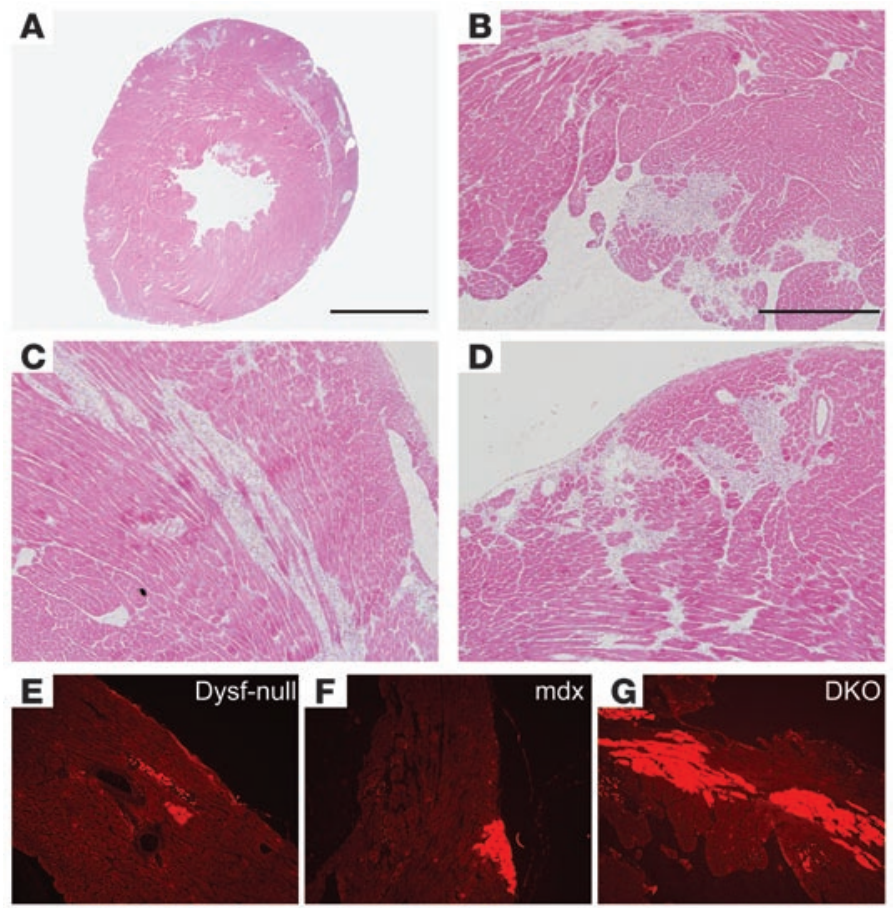

D
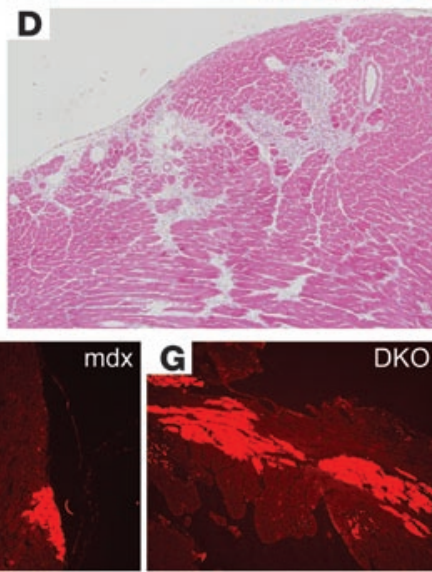

Figure 6

Large areas of acute necrosis and EBD uptake in the hearts of DKO mice following stress exercise. Large areas of acute necrosis were detected in the ventricular walls of 9-week-old DKO mice following stress exercise (A-D). Scale bars: $2 \mathrm{~mm}(\mathbf{A}) ; 500 \mu \mathrm{m}(\mathbf{B}-\mathbf{D})$. Hearts from DKO mice (G) had large areas of EBD uptake whereas those of $d y$ sferlin-null mice (E) showed only sporadic EBD uptake and those of $m d x$ mice $(\mathbf{F})$ only small focused areas of EBD uptake.

inin $\alpha 2$-chain antibody was purchased from Axxora (Alexis Biochemicals). Peroxidase-conjugated secondary antibodies were obtained from Roche Applied Science.

$R T$-PCR. Total RNA was extracted from the skeletal muscle and hearts of WT C57BL/6 mice, using RNAzol B (Tel-Test Inc.) according to the manufacturer's specifications. Total RNA $(2 \mu \mathrm{g})$ was randomly reverse transcribed to cDNA using SuperScript III Reverse Transcriptase (Invitrogen). PCR products were amplified using the following primers: no. 1, 5'-CTCCCCAATGTGAAGAAGGA-3' (forward), 5'-ACCTCCTGGAGTGGGATCTT-3' (reverse), product size: 242 bp; no. 2, 5'-TCGAAAATCTCTGCTACTGGAGGAG-3' (forward), 5'-CTCCACGCGCAGGATATCATCC-3' (reverse), product size: 306 bp (with a 42-bp in-frame splicing exon) or 264 bp; no. 3, 5'-TCAACGCACCTCTGCTAGAC-3' (forward), 5'-GAACGGCTCAGCTTCATCTC-3' (reverse), product size: $218 \mathrm{bp}$ or $311 \mathrm{bp}$ (with a novel 93-bp in-frame splicing exon). The bands were excised and DNA was extracted with the QIAquick Gel Extraction Kit (QIAGEN) and sequenced.

Generation of DKO mice. Mice were maintained at The University of Iowa Animal Care Unit in accordance with animal usage guidelines. All animal studies were authorized by the Animal Care Use and Review Committee of The University of Iowa. To generate DKO mice, male dysferlin-null mice (15) were mated to female $m d x$ mice, and F1 offspring were intercrossed to produce the F2 generation. Identification of the mutant mice was performed by PCR genotyping of genomic DNA prepared from mouse tail snips (42). Littermates from the same colony were used for experiments involving DKO mice.
Treadmill exercise. Animals were exercised using the Omnipacer Treadmill (model LC4/M-MGA/AT; AccuScan Instruments Inc.), which had an adjustable belt speed $(0-100 \mathrm{~m} / \mathrm{min})$, shock bars with adjustable amperage, and an on-and-off shock switch for each lane. Animals were exercised at $12 \mathrm{~m} / \mathrm{min}$ for 15 minutes and for $24 \mathrm{~m} / \mathrm{min}$ for 30 minutes. If an animal became exhausted, the shock bar of its lane was turned off and the animal was allowed to rest at the back of the treadmill for a short period of time. WT C57BL/6 $(n=10)$ and dysferlin-null mice (which had been backcrossed with C57BL/6 mice for 6 generations; $n=10)$ included approximately equal numbers of males and females. All mice were injected with EBD ( $0.5 \mathrm{mg}$ EBD $/ 0.05 \mathrm{ml}$ PBS) i.p. 8 hours before the exercise. Animals were injected with $50 \mu \mathrm{l} / 10 \mathrm{~g}$ body weight. All surviving animals were kept alive for 36-48 hours, and serial sections of cardiac muscle were studied for EBD uptake and histopathological signs of necrosis by routine H\&E staining.

Echocardiography. Echocardiography was performed on unsedated 54-week-old mice that had been randomly selected from C57BL/ 6 and dysferlin-null (backcrossed with C57BL6 for 6 generations) cohorts, respectively, by an investigator (R.M. Weiss) who was unaware of genotype. Two-dimensional images were acquired in short- and long-axis planes using a 15-MHz linear array transducer coupled to a Sonos 5500 imager (Philips) at a rate of approximately 200 frames per second and stored offline for later analysis. Short- and long-axis left ventricular silhouettes were visually identified and electronically planimetered by an investigator who was unaware of genotype in order to calculate end-diastolic and end-systolic volumes using the biplane area-length method previously validated in our laboratory (43). Where applicable, myocardial infarct size was estimated by electronic tracing of the portion of the left ventricular endocardial silhouette demonstrating akinesis and expressed as a percentage of the total of the entire left ventricle. After the initial echocardiography recording was made, the effect of stress exercise on cardiac function was examined by placing the ageand sex-matched WT and dysferlin-null mice on an uphill treadmill set at a $5^{\circ}$ vertical incline at a speed of $6 \mathrm{~m} / \mathrm{min}$ for 3 minutes, after which the speed was increased by $3 \mathrm{~m} / \mathrm{min}$ every 2 minutes until the mice were exhausted. The echocardiography was then immediately repeated.

Heart slice preparation and damage-repair assay. After each mouse (WT and dysferlin-null) was anesthetized by i.p. injection with $0.1 \mathrm{cc}$ ketamine, the chest was quickly opened and enough ice-cold cardioplegia solution (1-3 ml) was injected into the right atrium to stop the heartbeat. The heart was then removed and a heart slice from the left ventricle was obtained using 2 fine blades. The heart slices were incubated in the cold PBS solution and were warmed up to $37^{\circ} \mathrm{C}$ in aerated PBS solution before the damage-repair assay was initiated. The heart slices were placed in PBS containing $2.5 \mu \mathrm{M}$ FM1-43 (Invitrogen) with or without $1 \mathrm{mM} \mathrm{Ca}^{2+}$ in a custom-made glass chamber. Surface cardiomyocytes from the intact side of the slices were imaged with a 2-photon confocal laser-scanning microscope (LSM 510; Zeiss) coupled to a 10-W Argon/Ti:sapphire laser (Spectra-Physics Lasers Inc.). To induce membrane damage, a $300 \mu \mathrm{m} \times 5 \mu \mathrm{m}$ rectangular area of the sarcolemma on the surface cardiomyocytes was irradiated at full power for 10 seconds starting at $t=20$ seconds. Images were captured beginning 20 seconds before $(t=0)$ and continuing for 5 minutes after the irradiation at 10 -second intervals. For every image taken, the fluorescence intensity at the site of damage was measured using Zeiss LSM 510 imaging software (versions 3.2 and 4.0). Fibers that had no membrane resealing showed dye entry through the wound site over the entire course of the experiment whereas the dye influx halted within 1-2 minutes for the fibers that had resealed under the experimental conditions.

Subcellular membrane fractionation of cardiac muscle. Cardiac muscle membrane fractionation was performed in a manner similar to that pre- 
viously described for preparing skeletal muscle membrane fractions (44). Hearts from C57BL6 mice were removed and rinsed twice in cold PBS. The hearts were then minced and homogenized on ice 3 times (10 seconds each) using a Polytron homogenizer (Kinematica Inc.) set between levels 3 and 4 in a buffer containing $20 \mathrm{mM}$ HEPES, $250 \mathrm{mM}$ sucrose, $1 \mathrm{mM}$ EDTA, $5 \mathrm{mM}$ benzamidine, $1 \mu \mathrm{M}$ aprotinin $\mathrm{A}, 1 \mu \mathrm{M}$ pepstatin, $1 \mu \mathrm{M}$ leupeptin, and $1 \mathrm{mM}$ phenylmethylsulfonyl fluoride, $\mathrm{pH}$ 7.4. The homogenate was centrifuged at $2,000 \mathrm{~g}$ for 10 minutes. The pellet was discarded, and the supernatant was centrifuged at 9,000 $\mathrm{g}$ for 20 minutes. The resulting pellet (P1) was resuspended in PBS with the standard cocktail of protease inhibitors listed above and then analyzed for the presence of marker proteins by Western blotting. The supernatant was centrifuged at $180,000 \mathrm{~g}$ for 90 minutes. The resulting pellet was resuspended in PBS with protease inhibitors, loaded on a $10 \%-30 \%$ (wt/wt) continuous sucrose gradient (3-4 $\mathrm{mg}$ protein $/ 5 \mathrm{ml}$ gradient), and centrifuged at $285,000 \mathrm{~g}$ for 55 minutes in a SW40 rotor (Beckman Coulter). Gradients were separated into 13 fractions, starting from the top of the tube. The pellet of the sucrose-gradient centrifugation (P2) was resuspended in PBS and analyzed together with the gradient fractions. All centrifugations were performed at $4^{\circ} \mathrm{C}$.

HङE staining, Sirius red staining, and immunofluorescence analysis. Histopathology studies were performed as described previously $(8,45)$. Several H\&E-stained sections $(7 \mu \mathrm{m})$ throughout the entire ventricle and lower part of the atrium were prepared to characterize cardiac muscle pathology. Sirius red staining was performed in a manner similar to that of $\mathrm{H} \& \mathrm{E}$ staining. For quantitative analysis, images were split into 3 channels (red, green, and blue) using ImageJ software (version 1.36; http://rsb.info.nih. gov/ij/). The areas of the red and green regions were then calculated using ImageJ, and relative collagen was expressed as the ratio of red to green areas. Immunofluorescence staining was performed as described previously $(8,45)$. Anti-dysferlin antibody Hamlet was used at 1:40 dilution.

Immunoblotting analysis. Fifty sections $(7 \mu \mathrm{m})$ were prepared from the frozen hearts of different mouse models. The sections were then subjected to SDS extraction. SDS-extracted proteins were loaded, and Western blotting was performed as previously described (15).
Determination of cardiac troponin $T$. Serum samples from mice were obtained by tail bleeding according to The University of Iowa's institutional guidelines. Cardiac-specific troponin $\mathrm{T}(\mathrm{c} \operatorname{Tn} \mathrm{T})$ was measured by the Chemical Laboratory at the University of Iowa Medical Center. All assays were performed by technicians blinded to the source of the serum. The normal range for troponin $T$ levels in the serum was less than $0.03 \mathrm{ng} / \mathrm{ml}$.

Statistics. Data are presented as mean \pm SEM. Where appropriate, the significance of differences between multiple experimental groups was assessed using 1-way ANOVA with Bonferroni's post-tests, and the significance of differences between 2 experimental groups was assessed by Student's $t$ test (paired or unpaired where appropriate). A value of $P<0.05$ was accepted as significant.

\section{Acknowledgments}

We would like to thank Steve Moore for his critical comments and all the members of K.P. Campbell's laboratory for insightful comments and scientific contributions. We thank the University of Iowa Roy J. and Lucille A. Carver College of Medicine, the University of Iowa Central Microscopy Research Facility, and the Medical College of Georgia Imaging Core. This work was supported in part by the Senator Paul D. Wellstone Muscular Dystrophy Cooperative Research Center grant 1 U54 NS053672. K.P. Campbell is an investigator of the Howard Hughes Medical Institute.

Received for publication November 3, 2006, and accepted in revised form April 10, 2007.

Address correspondence to: Kevin P. Campbell, Howard Hughes Medical Institute, The University of Iowa, Roy J. and Lucille A. Carver College of Medicine, 4283 CBRB, 285 Newton Road, Iowa City, Iowa 52242, USA. Phone: (319) 335-7867; Fax: (319) 335-6957; E-mail: kevin-campbell@uiowa.edu.

Dimple Bansal's present address is: Brigham and Women's Hospital, Harvard Medical School, Boston, Massachusetts, USA.
1. Graham, R.M., and Owens, W.A. 1999. Pathogenesis of inherited forms of dilated cardiomyopathy. N. Engl. J. Med. 341:1759-1762.

2. Towbin, J.A., and Bowles, N.E. 2006. Dilated cardiomyopathy: a tale of cytoskeletal proteins and beyond. J. Cardiovasc. Electrophysiol. 17:919-926.

3. Muntoni, F., et al. 1993. Brief report: deletion of the dystrophin muscle-promoter region associated with X-linked dilated cardiomyopathy. N. Engl. J. Med. 329:921-925

4. Franz, W.M., et al. 2000. Association of nonsense mutation of dystrophin gene with disruption of sarcoglycan complex in X-linked dilated cardiomyopathy. Lancet. 355:1781-1785.

5. Piccolo, F., et al. 1995. Primary adhalinopathy: a common cause of autosomal recessive muscular dystrophy of variable severity. Nat. Genet. 10:243-245

6. Barresi, R., et al. 2000. Disruption of heart sarcoglycan complex and severe cardiomyopathy caused by beta sarcoglycan mutations. J. Med. Genet. 37:102-107.

7. Ben Hamida, M., Ben Hamida, C., Zouari, M., Belal, S., and Hentati, F. 1996. Limb-girdle muscular dystrophy 2C: clinical aspects. Neuromuscul. Disord. 6:493-494.

8. Coral-Vazquez, R., et al. 1999. Disruption of the sarcoglycan-sarcospan complex in vascular smooth muscle: a novel mechanism for cardiomyopathy and muscular dystrophy. Cell. 98:465-474.

9. Tsubata, S., et al. 2000. Mutations in the human $\delta$-sarcoglycan gene in familial and sporadic dilated cardiomyopathy. J. Clin. Invest. 106:655-662.

10. Cohn, R.D., and Campbell, K.P. 2000. Molecular basis of muscular dystrophies. Muscle Nerve. 23:1456-1471.

11. Durbeej, M., and Campbell, K.P. 2002. Muscular dystrophies involving the dystrophin-glycoprotein complex: an overview of current mouse models. Curr. Opin. Genet. Dev. 12:349-361.

12. Allen, D.G. 2001. Eccentric muscle damage: mechanisms of early reduction of force. Acta. Physiol. Scand. 171:311-319.

13. McNeil, P.L., and Khakee, R. 1992. Disruptions of muscle fiber plasma membranes. Role in exerciseinduced damage. Am. J. Pathol. 140:1097-1109.

14. Clarke, M.S., Caldwell, R.W., Chiao, H., Miyake, K., and McNeil, P.L. 1995. Contraction-induced cell wounding and release of fibroblast growth factor in heart. Circ. Res. 76:927-934.

15. Bansal, D., et al. 2003. Defective membrane repair in dysferlin-deficient muscular dystrophy. Nature. 423:168-172.

16. Lennon, N.J., et al. 2003. Dysferlin interacts with annexins $\mathrm{A} 1$ and $\mathrm{A} 2$ and mediates sarcolemmal wound-healing. J. Biol. Chem. 278:50466-50473.

17. Bashir, R, et al. 1998. A gene related to Caenorhabditis elegans spermatogenesis factor fer- 1 is mutated in limb-girdle muscular dystrophy type 2B. Nat. Genet. 20:37-42.

18. Liu, J., et al. 1998. Dysferlin, a novel skeletal muscle gene, is mutated in Miyoshi myopathy and limb girdle muscular dystrophy. Nat. Genet. 20:31-36.

19. Illa, I., et al. 2001. Distal anterior compartment myopathy: a dysferlin mutation causing a new muscular dystrophy phenotype. Ann. Neurol. 49:130-134.

20. Bittner, R.E., et al. 1999. Dysferlin deletion in SJL mice (SJL-Dysf) defines a natural model for limb girdle muscular dystrophy 2B. Nat. Genet. 23:141-142.

21. Ho, M., et al. 2004. Disruption of muscle membrane and phenotype divergence in two novel mouse models of dysferlin deficiency. Hum. Mol. Genet. 13:1999-2010.

22. Kuru, S., et al. 2004. A patient with limb girdle muscular dystrophy type 2B (LGMD2B) manifesting cardiomyopathy. Rinsho Shinkeigaku. 44:375-378.

23. Yilmazer, S., et al. 2006. Cardiac involvement in a group of patients with dysferlinopathy [abstract]. Neuromuscul. Disord. 16:S110.

24. Anderson, L.V., et al. 1999. Dysferlin is a plasma membrane protein and is expressed early in human development. Hum. Mol. Genet. 8:855-861.

25. Salani, S., et al. 2004. Developmental and tissuespecific regulation of a novel dysferlin isoform. Muscle Nerve. 30:366-374.

26. Soongswang, J., et al. 2002. Cardiac troponin T: its role in the diagnosis of clinically suspected acute myocarditis and chronic dilated cardiomyopathy in children. Pediatr. Cardiol. 23:531-535.

27. Duclos, F. 1998. Progressive muscular dystrophy in [alpha]-sarcoglycan-deficient mice. J. Cell Biol. 142:1461-1471. 
28. Ervasti, J.M., Ohlendieck, K., Kahl, S.D., Gaver, M.G., and Campbell, K.P. 1990. Deficiency of a glycoprotein component of the dystrophin complex in dystrophic muscle. Nature. 345:315-319.

29. Petrof, B.J., Shrager, J.B., Stedman, H.H., Kelly, A.M., and Sweeney, H.L. 1993. Dystrophin protects the sarcolemma from stresses developed during muscle contraction. Proc. Natl. Acad. Sci. U. S. A. 90:3710-3714.

30. Clarke, M.S., Khakee, R., and McNeil, P.L. 1993. Loss of cytoplasmic basic fibroblast growth factor from physiologically wounded myofibers of normal and dystrophic muscle. J. Cell Sci. 106:121-133.

31. Hoffman, E.P., Brown, R.H., Jr., and Kunkel, L.M. 1987. Dystrophin: the protein product of the Duchenne muscular dystrophy locus. Cell. 51:919-928.

32. Sicinski, P., et al. 1989. The molecular basis of muscular dystrophy in the $\mathrm{mdx}$ mouse: a point mutation. Science. 244:1578-1580.

33. Cox, G.A., Phelps, S.F., Chapman, V.M., and Chamberlain, J.S. 1993. New mdx mutation disrupts expression of muscle and nonmuscle isoforms of dystrophin. Nat. Genet. 4:87-93.

34. Fuster, V., Badimon, L., Badimon, J.J., and Chesebro, J.H. 1992. The pathogenesis of coronary artery disease and the acute coronary syndromes (1). N. Engl. J. Med. 326:242-250.

35. Davis, D.B., Doherty, K.R., Delmonte, A.J., and McNally, E.M. 2002. Calcium-sensitive phospholipid binding properties of normal and mutant ferlin C2 domains. J. Biol. Chem. 277:22883-22888.

36. McNeil, A.K., Rescher, U., Gerke, V., and McNeil, P.L. 2006. Requirement for annexin A1 in plasma membrane repair. J. Biol. Chem. 281:35202-35207.

37. Chakrabarti, S., et al. 2003. Impaired membrane resealing and autoimmune myositis in synaptotagmin VII-deficient mice. J. Cell Biol. 162:543-549.

38. Takahashi, T., et al. 2006. A case of dysferlinopathy presenting choreic movements. Mov. Disord. 21:1513-1515.

39. Galvin, J.E., Palamand, D., Strider, J., Milone, M., and Pestronk, A. 2006. The muscle protein dysferlin accumulates in the Alzheimer brain. Acta. Newropathol. 112:665-671.
40. Izzedine, H., et al. 2006. Loss of podocyte dysferlin expression is associated with minimal change nephropathy. Am. J. Kidney Dis. 48:143-150.

41. Davis, D.B., Delmonte, A.J., Ly, C.T., and McNally, E.M. 2000. Myoferlin, a candidate gene and potential modifier of muscular dystrophy. Hum. Mol. Genet. 9:217-226.

42. Amalfitano, A., and Chamberlain, J.S. 1996. The mdx-amplification-resistant mutation system assay, a simple and rapid polymerase chain reaction-based detection of the $\mathrm{mdx}$ allele. Muscle Nerve. 19:1549-1553.

43. Hill, J.A., et al. 2000. Cardiac hypertrophy is not a required compensatory response to short-term pressure overload. Circulation. 101:2863-2869.

44. Zhou, M., et al. 1998. Insulin-dependent protein trafficking in skeletal muscle cells. Am. J. Physiol. 275:E187-E196.

45. Cohn, R.D., et al. 2001. Prevention of cardiomyopathy in mouse models lacking the smooth muscle sarcoglycan-sarcospan complex. J. Clin. Invest. 107:R1-R7. 